the ratio between the error and the difference of latitude must be as small as possible, that is, the factor

$$
\frac{c_{S} \sin M+e_{M} \sin S}{P \cos (M-P) \sin S}
$$

must be small. Clearly $\sin S$ should not be small (the Sun cannot be near the meridian) and neither should $\cos (M-P)$ (the Moon also cannot be near to the meridian); the optimum conditions are when the Sun and Moon are both near the prime vertical, preferably one east and one west of the meridian. The expression is independent of the angle of cut of the two position lines, but obviously too small an angle must be avoided.

In Mr. Chichester's example, $P$ is $72^{\circ} 5, M$ is about $280^{\circ}$ and $S$ about $25^{\circ}$; so that the conditions are good, although the angle of cut is small and the Moon, only 60 hours before New Moon, must have been difficult to observe. Actually, the errors in longitude corresponding to errors of $I^{\prime}$ in the observed altitudes (or, of course, also in the calculated altitudes and in the altitude corrections) are about $30^{\prime}$ for both the Sun and the Moon-almost the maximum precision attainable; the error of $6^{\prime}$ is thus fortuitously small. For such calculations the working unit in altitude should certainly be 0 ! i t the use of sight reduction tables for air navigation, with a tabular precision of $\mathrm{I}^{\prime}$, introduces unnecessary sources of error.

It is curious that this method has not been used before; or, if it has, is not well known. Perhaps it is a consequence of the fact that the present position-line fix only dates from the time when 'lunars' had already become obsolete.

\title{
The Impact of Radar on the Rule of the Road
}

\section{Commander P. Clissold}

The International Regulations for Preventing Collisions at Sea, 1960, became effective on I September 1965 and, in spite of the sound advice contained in the Annex, it already seems doubtful whether the Steering and Sailing Rules will prove efficacious in preventing collisions. It is clear that a growing body of opinion considers that changes of some sort are necessary; the April number of this Journal, for instance, contains interesting proposals by Captain J. F. Kemp.

The Steering and Sailing Rules for vessels proceeding so as to involve risk of collision are based upon the principle that one should keep out of the way and the other should keep her course and speed-with two exceptions : when two powerdriven vessels meet end-on or nearly end-on, and when two vessels find themselves so close that collision cannot be avoided by the action of the give-way vessel alone.

This principle cannot be applied when vessels are navigating by radar for no ship can be sure whether or not she has been observed by another; this the 1960 
amendment admits, stating that Rules 17 to 24 apply only when vessels are in sight of one another. For much of the time therefore, and at the most dangerous time, these Rules are of no use to the navigator. He has complete freedom of manœuvre, but no guidance as to what this should be except the not very forceful advice contained in the Annex that 'an alteration of course to starboard, particularly when vessels are approaching apparently on opposite or nearly opposite course, is generally preferable to an alteration to port'.

Even in clear weather there is likely to be a growing number of cases where the Steering Rules cannot be applied. Very fast craft such as hovercraft and hydrofoils, if approaching a ship on a collision course, must take avoiding action whether they are the 'give-way' vessels or not, simply because the other is too slow to manouvre effectively within the available time. Fast cross-channel packets no doubt already do this; seaplanes on the water are directed to do it.

Peering into the future for a moment, if ships are ever navigated automatically, a rule based on a mathematical foundation (the present ones are not) will have to be adopted.

It is clear that conditions at sea have changed greatly since the Rules were first formulated and the argument that the Regulations have been found adequate to prevent collisions in the past does not mean that they are suitable for present-day navigation, or for the future. Within a fortnight of writing this note there were six collisions in the English Channel alone. Since the navigators of those ships were doing their best to avoid collisions, and were certainly acquainted with the Rules, it is at least possible that inadequacies in the Rules themselves contributed to the collisions. In the Summary of Collisions appended to Captain Wylie's paper counteracting helm actions had been employed in one third of the cases. ${ }^{1}$ Even the advice contained in the Annex that 'if a close quarter situation is imminent, the most prudent action may be to take all way off the vessel', though true, is not without its drawbacks in crowded waters. The flow of traffic is interrupted, ships astern of the vessel stopping crowd up on her and the area becomes still more congested.

Airmen cannot 'take all way off the vessel' and have had to re-think the problem ; seamen could do the same. Rules, to be of much use, should be applicable to all cases at all times, and not be more restrictive than absolutely necessary. One is led to the inescapable conclusion that:

(i) the principle of one ship standing on and the other keeping clear has become obsolete with the general use of radar navigation and must be replaced by the principle that it is the duty of every power-driven vessel involved in a risk of collision to take avoiding action.

(ii) to prevent this action from being cancelled by the other vessel, the manœurre must be in accordance with some accepted rule.

If we continue to use the traditional 'keep to starboard' as a guide, the manouvre required must ensure that the sight-line would rotate in an anticlockwise direction if the other vessel stood on. Calvert has pointed this out and, with Hollingdale, has demonstrated its mathematical correctness $2,3,4$.

Once we have accepted the necessity of this reform we find that it is possible to replace with a single new Rule, for power-driven vessels, the present Rules 1 8, 19, 21, 23 and 24. Using the phraseology of the Rules this might read: 'When a power-driven vessel is proceeding in such a direction as to involve risk of col- 
lision with another, she shall alter course, or speed, or both, so that the compass bearing (read in 3 figures) will decrease.'

This succinct, but perhaps daunting, expression can be clarified by adding "When the bearing of the other vessel is:

(a) forward of the beam, an alteration of course should be to starboard;

(b) abaft the beam, an alteration of course should be to port;

(c) to starboard, an alteration of speed should be a reduction;

(d) to port, an alteration of speed should be an increase;

(e) about ahead, an alteration of course will be more effective than an alteration of speed;

$(f)$ about beam, an alteration of speed will be more effective than an alteration of course.'

It would be desirable to retain the second part of Rule 21 (slightly altered) 'When, from any cause, a vessel finds herself so close that collision cannot be avoided by following this Rule, she shall take such action as will best help to avert collision.' This is to allow for unpredictable encounters. For example, in Case III (Fig. $3^{b}$ ), in Captain Kemp's paper ${ }^{5}$ it seems probable that the ships are already too close for the overtaken one to take any helpful action except by quickly increasing speed-if she can. If, as Captain Wylie points out, an alteration of course to port will impale her upon the other's bows, an alteration of course to starboard will swing her stern on to them.

Captain Wylie also points out that the present Rule of one vessel keeping her course and speed (when in sight of another) is helpful to the give-way vessel because it removes any doubt of the other's movements and prevents unnecessary manœuvring. Rule 22 (modified) should retain this advantage. 'When a powerdriven vessel is proceeding in such a direction as to involve risk of collision with another, she shall, if the bearing of the other vessel is to starboard and forward of the beam, so far as possible take positive early action to avoid crossing ahead of her.'

Since, when out of sight of one another, ships have at present a free hand, there is no reason why this rule should not be adopted now; but unless all ships follow it there will always be the danger that one will manœuvre in the contrary sense.

I may end by quoting Mr. Calvert, to whom all navigators, aerial and marine, owe a debt. "For twenty years or more airmen meekly accepted censure for "pilot-errors" in accidents in which adequate guidance simply did not exist . . I I have seen the mental misery and broken careers which result when conscientious and competent people have to work with tools which, unknown to themselves, are not suitable for the jobs they have to do.'

A good Rule will not alone be sufficient to avert collisions, but it is a necessary factor in the solution of the problem. We need routing in congested areas; improvements in radar equipment and its use and always, of course, care and common-sea-sense in their application.

\section{REFERENCES}

1 Wylie, F. J. (1965). Legal aspects of radar and collision. This Journal, 18, 203.

2 Calvert, E. S. (1960). Manœuvres to ensure the avoidance of collision. This Journal, 13, 127.

3 Calvert, E. S. (1961). A comparison of two systems for avoiding collision. This Journal, 14, 379. 
4 Hollingdale, S. H. (1961). The mathematics of collision avoidance in two dimensions. This Journal, 14, 243.

$5 \mathrm{Kemp}$, J. F. (1965). Some suggestions on the rules for preventing collision at sea. This Journal, 18, 233.

\section{'The Sector Rule and the Collision Problem'}

Captain García-Frías has made the following comments on the discussion of his recent paper (this Journal, 18, I4I) contributed by E. S. Calvert and S. H. Hollingdale.

Captain García-Frías observes that while Calvert and Hollingdale recognize that this paper combines his earlier suggestion for a sector rule with a set of manœuvring rules, they have failed to recognize the fundamental distinction between the structural and operational aspects of an encounter; his proposed manœuvring rules deal with the operational aspect. These rules differ from the mancuvres they have themselves proposed in that they depend only on the bearing of the target as seen on the radar at a distance of 2 miles; they derive from his sector rule and do not require a quantitative estimate of the miss distance. His rules are only the same as their manœuvres for the case of a steady bearing since their manœuvres also require the sign of the miss distance.

They also fail to recognize the extent to which his sector rule can take the place of 'aspect' and 'the seaman's eye', in a visual encounter, when shaping a prudent approach by radar only. It is certainly true that his manœuvring rules and their system of mancuvres require the same basic information from the radar; they are the essential elements for any solution, but with his proposed rules the information provided by the radar is applied directly and without the analytical procedure which their manœuvres require.

The acceptance of the 2-mile range is not a matter of cooperation between the vessels involved, it is the distance judged to be necessary for prudential action to prevent the distance closing to one mile. To propose minimum and maximum speeds for vessels with and without radar is the only way to meet the problem where radarless vessels are concerned and the principle is already acceptable for hovercraft \&c. A certain degree of cooperation between vessels is in any case inherent in the Steering and Sailing Rules. To clear up any confusion between the 2-mile and 2.5 -mile limits it may be repeated that Rule $16(\mathrm{c})$ prescribes two miles as the distance within which both the vessels concerned should take proper action to check the approach. The $2 \cdot 5$-mile range is only mentioned in Rule (a) and relates to only one of the vessels concerned.

The proposed Rule 16 (c) does not, as they suppose, require a vessel to alter speed or make a larger turn than $60^{\circ}$ port or $120^{\circ}$ starboard when the target is two miles distant; changes in speed are optional and large changes in course are only prescribed 'if necessary', the sector rule being kept as a last resort. They are also wrong in supposing that initial course and speed can only be resumed when it is clear that the danger is over; the vessel will in fact return to her former course 